УДК 624.05

DOI https://doi.org/10.32782/2664-0406.2020.37.2

\title{
Борисов А.A.
}

к.т.н., доцент кафедры технологии строительного производства,

Одесская государственная академия строительства и архитектуры, г. Одесса

\section{Кирилюк С.В.}

к.т.н., заведующий лабораторией кафедры технологии строительного производства, Одесская государственная академия строительства и архитектуры, г. Одесса

\section{ОПРЕДЕЛЕНИЕ ТЕХНОЛОГИЧЕСКИХ ПАРАМЕТРОВ УСТРОЙСТВА ПРОТИВОФИЛЬТРАЦИОННОГО ЭКРАНА}

\begin{abstract}
Анотація. Влаштування протифільтращійних екранів $є$ одним із найпрогресивніших способів боротьби з підземними водами. Розглянуто випадок відсутності водоупора, на досяжній глибині, під час влаштування суцільного протифільтрачійного екрана. Як альтернатива розроблена технологія влаштування сущільного протифільтращійного екрана під будівлею або спорудою, які схильні до підтоплення, з використанням двонапрямлених шнеків із поперечним розташуванням у свердловині. Досліджено три швидкості розробки плоскою свердловини шнеком із поперечним розташуванням. Крім зміни швидкості, варіювалися також навантаження, що діють на шнек у напрямі розробки від власної ваги і з додатковою вагою. Шнек приводився до руху електроінструментом для фіксування енергоспоживання у процесі розробки за допомогою енергометру. Зростання швидкості обертання $і$ навантаження на шнек призводять до збільшення швидкості розробки і споживаної потужності електроінструменту. Виявлено залежності швидкості розробки грунту від частоти обертання шнека і від впливу додаткового навантаження на шнек. Двонапрямлений шнек, залежно від напряму обертання, за або проти годинникової стрілки, може виконувати розробку або перемішування розчину з грунтом при створенні проти фільтраційного екрана. Крок зупинки під час переміщення по висоті становив підлогу діаметра шнека для перемішування розчину. Наведено залежність швидкості бетонування від швидкості обертання шнека. Отримані експериментальні дані були проаналізовані за допомогою програмного комплексу СотрЕХ. Складено матриці варіювання факторів у процесі визначення пластичної мічності зразків, дослідження технологічних параметрів швидкості розробки грунту і дослідження технологічних параметрів швидкості бетонування.

Ключові слова: протифільтрачійний екран, розробка грунту, підтоплення територій, буріння свердловин.
\end{abstract}

Постановка проблемы. Эффективным способом защиты зданий и сооружений от подземных вод является устройство вертикальных противофильтрационных экранов. Шнек буровой установки направлен вдоль скважины [1-3], и устройство антифильтрационного экрана трудоемко из-за большого количества рядом расположенных скважин.

В экспериментальном исследовании шнек расположен перпендикулярно направляющим скважинам и используется для разработки, транспортировки и смешивания грунта с твердеющими растворами. Как альтернатива может применяться разработанная технология устройства сопряженного проти- вофильтрационного экрана под существующими зданиями и сооружениями с использованием шнекового оборудования.

Анализ последних достижений. При сооружении противофильтрационных экранов более эффективно бурение скважин прямоугольного сечения. С помощью прямоугольного сечения сохраняется постоянная толщина экрана, что в итоге приводит к уменьшению объемов разрабатываемого грунта и экономии твердеющего раствора. Конструкция бурового инструмента с криволинейной рабочей поверхностью предложена в Казахском политехническом институте [4]. Конструкция бурового инструмента предназ- 

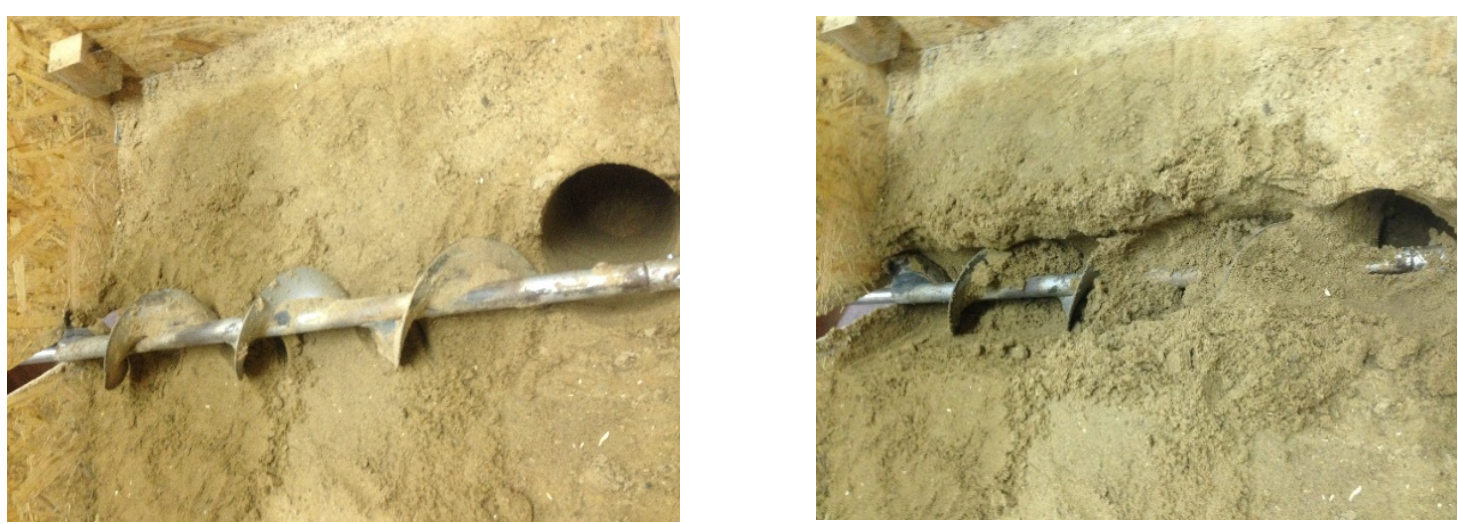

Рис. 1. Разработка грунта в направляющую скважину

начена для разработки вертикальных скважин прямоугольного сечения и может быть использована при сооружении противофильтрационного экрана с водоупором. При отсутствии водоупора на досягаемой глубине использование горизонтально направленного бурения и использование шнекового оборудования позволит создать противофильтрационный экран под существующим зданием и сооружением [5; 6].

Цель работы. Определить зависимости скорости разработки грунта и бетонирования разработанной технологии устройства сплошного противофильтрационного экрана под существующим зданием или сооружением, которые подвержены подтоплению, с использованием двунаправленных шнеков.

Результаты исследования. При вращении шнека за часовой стрелкой производится разработка грунта в направляющую скважину (рис. 1).

При разработке грунта использовалось 3 скорости:
1) высокая - 1,5 об/с (90 об/мин);
2)средняя - 1 об/с (60 об/мин);
3)низкая - 0,5 об/с (30 об/мин).

В качестве привода для вращения однонаправленной части шнека использовался перфоратор (рис. 2).

При разработке с разной частотой вращения (низкой, средней и высокой) энергометром (ваттметром) замерялась мощность, потребляемая приводом.

Мощность колебалась от 245 до 560 Вт, соответственно, при низкой и высокой скорости вращения (разработка под собственным весом шнека) (рис. 3).

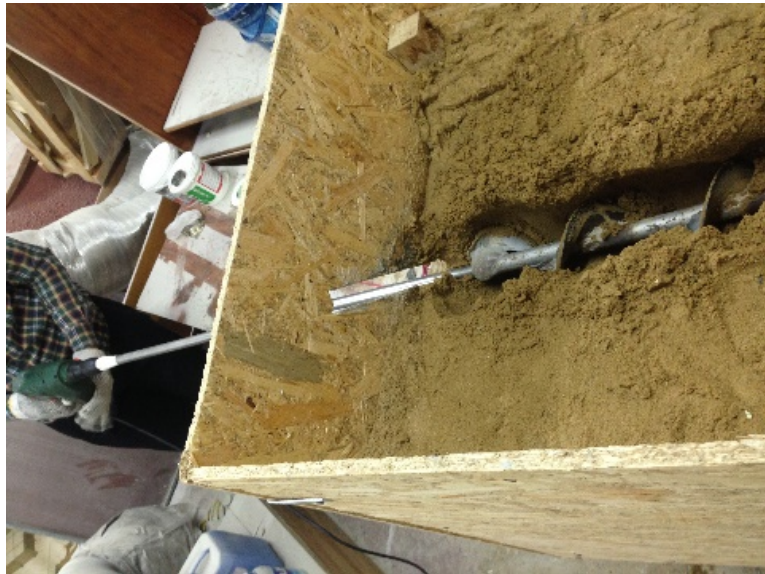

Рис. 2. Вращение шнека при помощи перфоратора

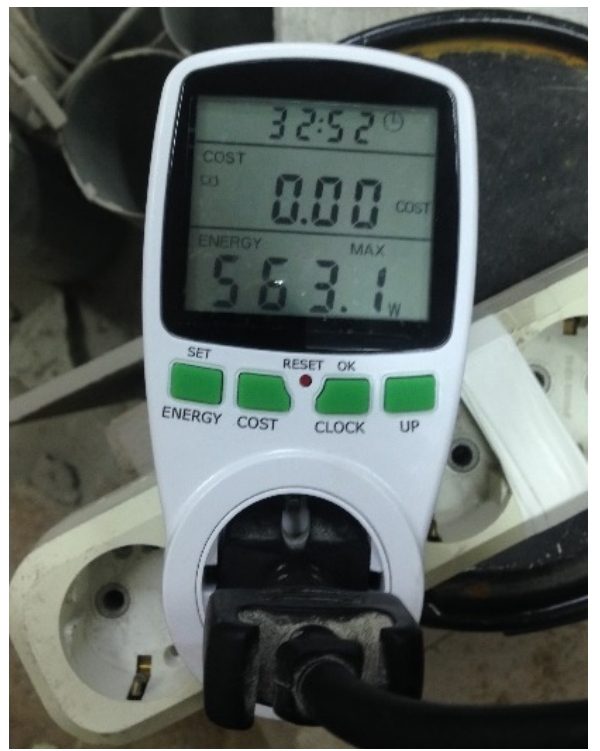

Рис. 3. Измерение мощности при различной частоте вращения шнека

При вращении шнека со скоростью выше 2 об/с наблюдались вибрации и обрывы грун- 
та, в связи с этим не рекомендуется превышать данную частоту вращения.

Разработка производилась под собственным весом шнека - 3,2 кг.

В процессе бурения при каждой из вышеуказанных скоростей замерялась скорость разработки грунта, а именно: количество времени за которое шнек проходит 1 м при непрерывной разработке грунта. В результате были получены зависимости скорости разработки грунта от скорости вращения шнека (рис. 4).

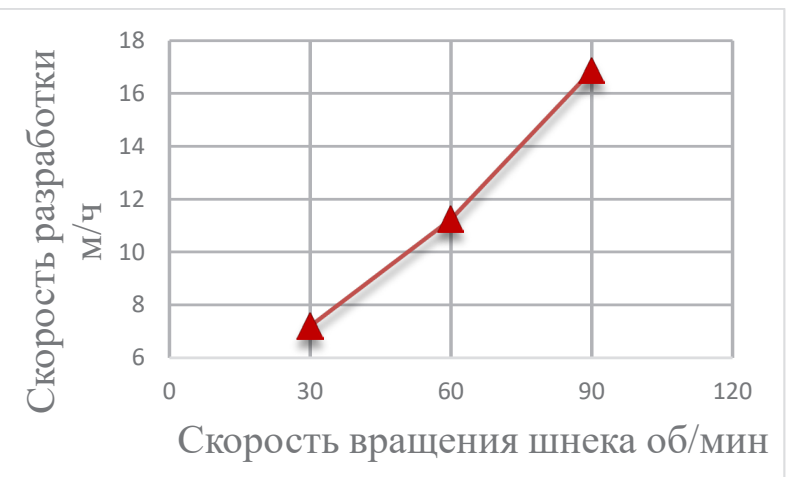

Рис. 4. Зависимость скорости разработки грунта от частоты вращения шнека

Для изменения скорости разработки, кроме собственного веса шнека, прикладывается дополнительный вес, который приводит к увеличению крутящего момента, требуемого для вращения шнека.

Дополнительный вес прикладывается с обеих сторон ящика к валу шнека грузами через подшипники по направляющим либо с помощью электронного динамометра (рис. 5), чтоб минимизировать влияние сил трения. Масса грузов изменяется от 0,5 до 3,5 кг, увеличивая врезание лопастей шнека в грунт и скорость разработки скважины.

Было исследовано влияние тянущего усилия (доп. веса) при частоте 30 об/мин.

Нагрузка при бурении составлялась из собственного веса шнека плюс дополнительный. Было выделено 5 режимов бурения с использованием дополнительного тянущего усилия, при этом лопасти шнека врезались в грунт на разные величины:

1) без дополнительного веса - врезание в грунт лопастей - 1,5 см;
2) груз 0,5 кг - 1,5-2 см;
3) груз 1 к г- 2 см;
4) груз 2 кг - 3 см;
5) груз 3,5 кг - 4,5-5 см.

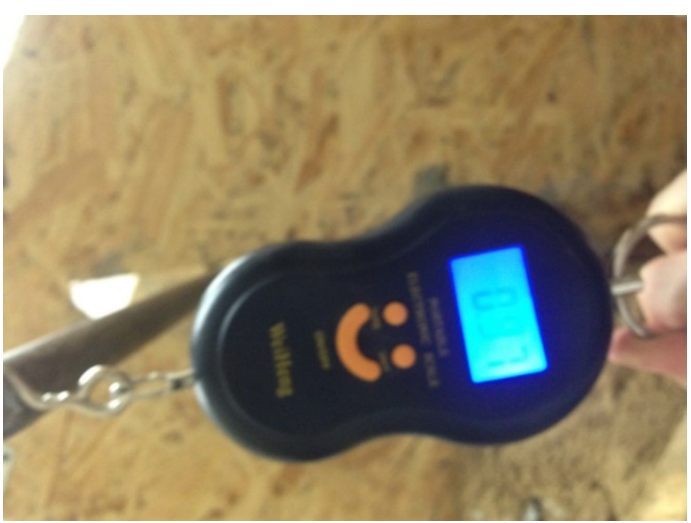

Рис. 5. Приложение тянущего усилия грузом через подшипники вдоль направляющей скважины

При дополнительном весе 3,5 кг и более наблюдалось значительное увеличение крутящего момента и погружение лопастей достигло максимума (до оси вращения шнека). В связи с тем, что груз дает увеличение скорости разработки за счет большего врезания лопастей, а при 3,5 кг врезание лопастей достигло максимума применение тянущего усилия свыше 3,5 кг при бурении вниз (вдоль скважины) и горизонтально не является целесообразным.

В процессе бурения при каждом из вышеуказанных режимов работы замерялась скорость бурения, а именно - количество времени за которое шнек проходит 1 м при непрерывной разработке грунта. В результате были получены зависимости скорости разработки грунта от тянущего усилия при скорости вращения шнека 30 об/мин (рис. 6).

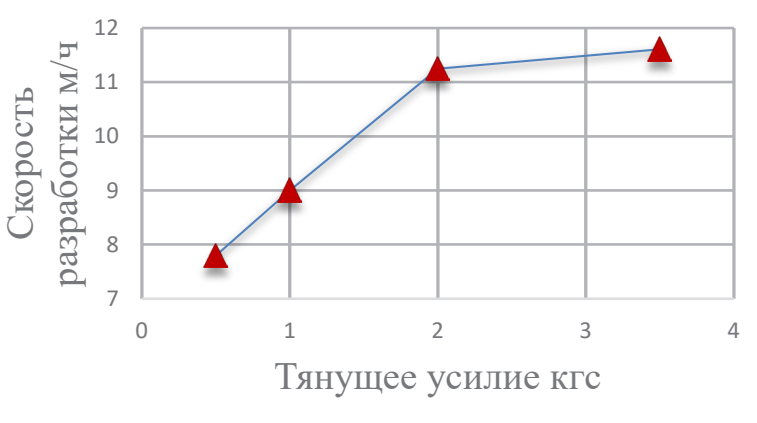

Рис. 6 Зависимость скорости разработки грунта от тянущего усилия при частоте вращения 30 об/мин

При вращении шнека против часовой стрелки производится бетонирование со стоянками каждые 5 см для перемешивания подаваемого раствора и грунта (рис. 7). 

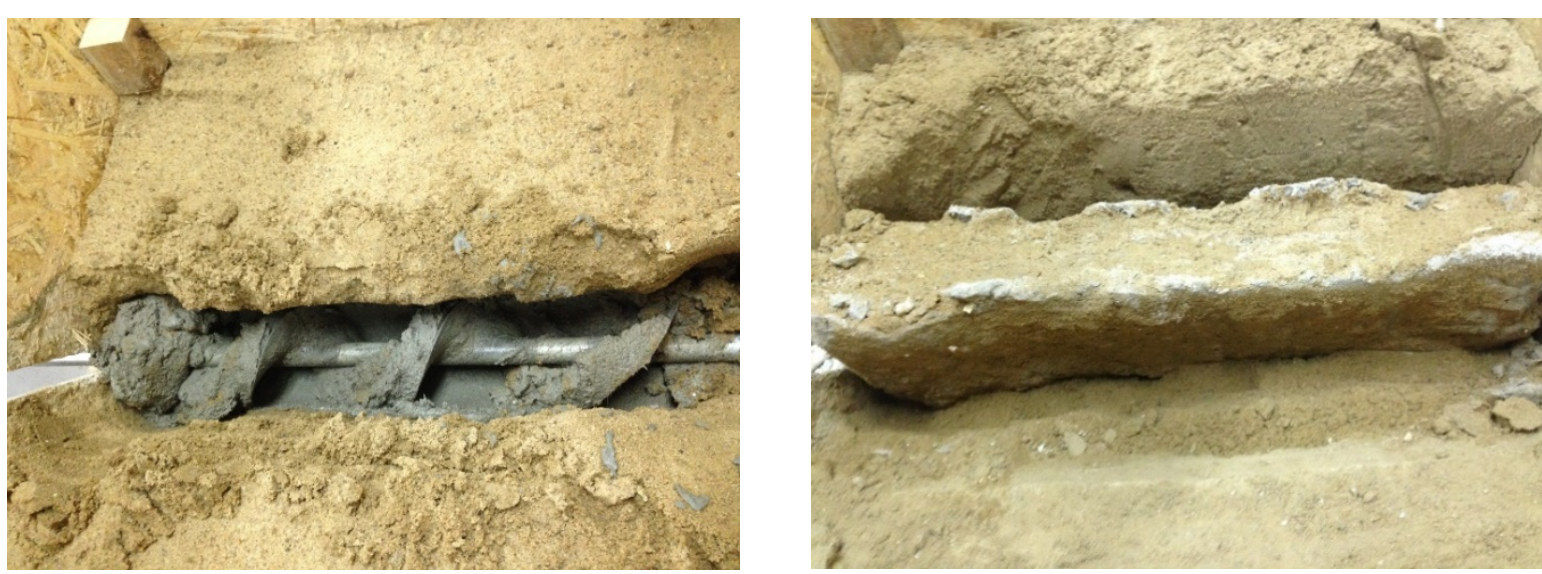

Рис. 7. Процесс перемешивания раствора и готовый очищенный участок экрана

Для определения скорости бетонирования при различных скоростях вращения шнека (высокой, средней и низкой) засекалось время перемешивания одной стоянки шнека. Стоянки производятся каждые 5 см (половина диаметра шнека) для тщательного перемешивания подаваемого раствора и грунта до образования однородной монолитной массы.

На 1 м приходится 22 стоянки. При различной частоте вращения шнека время одной стоянки и переход на следующую составляет:

1) 30 об/мин - 30 с;

2) 60 об/мин - $19 \mathrm{c}$;

3) 90 об/мин - 15 с.

Приведя данные к 1 м бетонирования получаем, соответственно, 5,5 м/ч, 8,6 м/ч и $10,9 \mathrm{M} /$ ч.

На рисунке 8 показана зависимость скорости бетонирования от скорости вращения шнека.

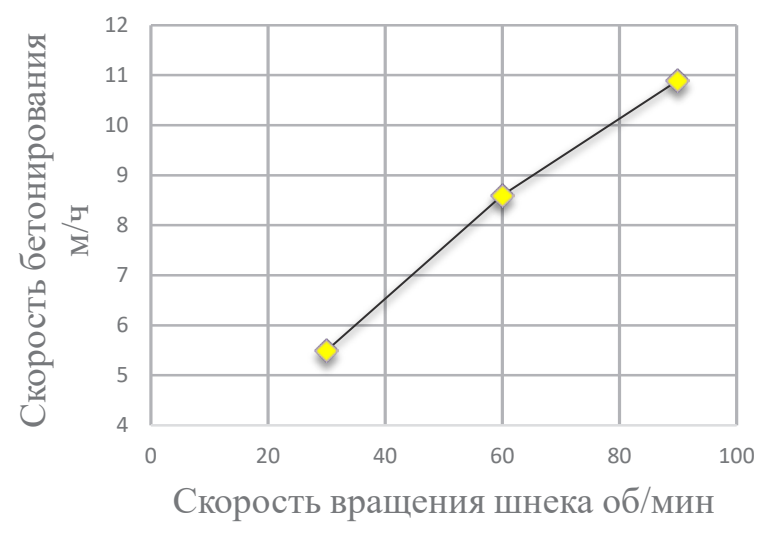

Рис. 8. Зависимость скорости бетонирования от скорости вращения шнека
Анализ полученных экспериментальных данных был проведен с помощью программного комплекса CompEX 2009.01. Составлены матрицы варьирования факторов.

Уровни изменения факторов при определении пластической прочности $\left(\mathrm{y}_{2}\right)$ образцов приведены в таблице 1.

Таблица 1. Уровни изменения факторов при определении пластической прочности

\begin{tabular}{|c|c|c|c|}
\hline \multirow{2}{*}{ Наименование фактора } & \multicolumn{3}{|c|}{$\begin{array}{l}\text { Значения } \\
\text { факторов }\end{array}$} \\
\cline { 2 - 4 } & -1 & 0 & 1 \\
\hline Концентрация фибры $\mathrm{X}_{1}$ & $3 \%$ & $6 \%$ & $9 \%$ \\
\hline Концентрация бентонита $\mathrm{X}_{2}$ & $5 \%$ & $10 \%$ & $15 \%$ \\
\hline $\begin{array}{c}\text { Концентрация жидкого } \\
\text { стекла Х }\end{array}$ & $6 \%$ & $12 \%$ & $18 \%$ \\
\hline
\end{tabular}

Уровни изменения факторов при исследовании технологических параметров скорости разработки грунта $\left(\mathrm{y}_{4}\right)$ в таблице 2 .

Таблица 2. Уровни изменения факторов при исследовании технологических параметров скорости разработки грунта

\begin{tabular}{|c|c|c|c|}
\hline \multirow{2}{*}{$\begin{array}{c}\text { Наименование } \\
\text { фактора }\end{array}$} & \multicolumn{3}{|c|}{ Значения факторов } \\
\hline & -1 & 0 & 1 \\
\hline $\begin{array}{c}\text { Угловая скорость } \\
\mathrm{X}_{1} \\
\end{array}$ & 0,5 об/с & 1 об/с & 1,5 об/c \\
\hline Тяговое усилие $\mathrm{X}_{2}$ & 3,2 кгс & 4,2 кгс & 5,2 кгс \\
\hline
\end{tabular}

Уровни изменения факторов при исследовании технологических параметров скорости бетонирования $\left(\mathrm{y}_{5}\right)$ приведены в таблице 3. 
Таблица 3. Уровни изменения факторов при исследовании технологических параметров скорости бетонирования

\begin{tabular}{|c|c|c|c|}
\hline \multirow{2}{*}{$\begin{array}{c}\text { Наименование } \\
\text { фактора }\end{array}$} & \multicolumn{3}{|c|}{ Значения факторов } \\
\hline & -1 & 0 & 1 \\
\hline $\begin{array}{c}\text { Угловая скорость } \\
\mathrm{X}_{1} \\
\end{array}$ & 0,5 об/c & 1 об/с & 1,5 об/c \\
\hline $\begin{array}{c}\text { Скорость подачи } \\
\text { состава } \mathrm{X}_{2}\end{array}$ & $30 \mathrm{~m}^{3} / \mathrm{\varphi}$ & $40 \mathrm{M}^{3} / \mathrm{\varphi}$ & $50 \mathrm{~m}^{3} / \mathrm{ч}$ \\
\hline
\end{tabular}

Выводы. Определены и приведены зависимости скорости разработки грунта от частоты вращения шнека, от тянущего усилия при частоте вращения 30 об/мин и скорости бетонирования от скорости вращения шнека.

Составлены матрицы варьирования факторов при определении пластической прочности, исследовании технологических параметров скорости разработки грунта и исследовании технологических параметров скорости бетонирования.

1. Кантович Л.И., Хазанович Г.Ш. Машины для горностроительных работ : Учебное пособие. Москва : Издательство «Горная книга», 2011. 445 с.

2. Бунтман А.Д. Об использовании противофильтрационных завес для защиты котлованов от притока грунтовых вод. Энергетическое строительство. 1978. № 2. С. 86-87.

3. Бадьин Г.М., Сычев С.А. Современные технологии строительства и реконструкции зданий. СанктПетербург : БХВ-Петербург, 2013. 288 с.

4. Лысенко В.М., Ситников В.Д., Ситников Е.В. Буровой инструмент для образования прямоугольного сечения / патент № 400699, 1973.

5. Менейлюк А.И. Разработка технологии устройства сплошного противофильтрационного экрана / Менейлюк А.И., Петровський А.Ф., Борисов А.А., Кирилюк С.В. Нові технологій в будівництві. 2018. Вип. 34. С. 89-94.

6. Спосіб спорудження екрана під спорудою: пат. на корисну модель 133819 Україна : МПК Е02D 31/00, № u 2018 10960; заяв. 06.11.2018; опубл. 25.04.2019, Бюл. № 8 .

\title{
References
}

1. Kantovich L.I., Hazanovich G.Sh. Mashinyi dlya gornostroitelnyih rabot. Uchebnoe posobie. M.: Izdatelstvo «Gornaya kniga», 2011. 445 p.

2. Buntman A.D. Ob ispolzovanii protivofiltratsionnyih zaves dlya zaschityi kotlovanov ot pritoka gruntovyih vod. Energeticheskoe stroitelstvo. 1978. \# 2. P. 86-87.

3. Badin G.M., Syichev S.A., Sovremennyie tehnologii stroitelstva i rekonstruktsii zdaniy. SPb: BHV-Peterburg, 2013. $288 \mathrm{~s}$.

4. Lyisenko V.M., Sitnikov V.D., Sitnikov E.V. Burovoy instrument dlya obrazovaniya pryamougolnogo secheniya / patent \# 400699, 1973.

5. Meneylyuk A.I. Razrabotka tehnologii ustroystva sploshnogo protivofiltratsionnogo ekrana / Meneylyuk A.I., Petrovskiy A.F., Borisov A.A., Kirilyuk S.V. Novi tehnologiyi v budivnitstzi. 2018. Vip. 34. P. 89-94.

6. Sposib sporudzhennya ekrana pid sporudoyu: pat. na korisnu model 133819 UkraYina : MPK E02D 31/00, \# u 2018 10960; zayav. 06.11.2018; opubl. 25.04.2019, Byul. \#8.

\section{DETERMINATION OF TECHNOLOGICAL PARAMETERS FILTER SCREEN DEVICES}

\begin{abstract}
The device of antifiltration screens is one of the most progressive ways of struggle against underground waters. The case of absence of water resistance, at the reached depth, at the device of the continuous antifiltration screen is considered. Alternatively, a solid anti-leakage screen technology has been developed under an existing building or structure that is subject to flooding, using bidirectional augers with a transverse arrangement in the well. Three specific speeds of flat well auger development with a transverse arrangement have been studied. In addition to the change in speed, the load acting on the auger in the direction of development from its own weight and with additional weight also varied. The auger was driven by a power tool to record energy consumption during development, using an energy meter. Increasing the speed of rotation and the load on the auger lead to an increase in the speed of development and power consumption of the power tool. The dependences of the speed of soil development on the frequency of rotation of the auger and on the impact of additional load on the auger are revealed. The bidirectional auger, depending on the direction of rotation, clockwise or counterclockwise, can develop or mix the solution with
\end{abstract}


the soil when creating an anti-filtration screen. The stopping step, when moving in height, was half the diameter of the auger for mixing the solution. The dependence of the concreting speed on the screw rotation speed is given. The obtained experimental data were analyzed using the CompEX software package. Matrices of variation of factors at definition of plastic durability of samples, at research of technological parameters of speed of development of soil and at research of technological parameters of speed of concreting are made.

Key words: anti-filtration screen, development of soil, flooding of territories, drilling of wells.

\section{Borisov A.A.}

Ph.D., Associate Professor at the Department of Technology of Building Production, Odessa State Academy of Building and Architecture, Odessa

Kirilyuk S.V.

Ph.D., Head of Laboratory Department of Construction Technology,

Odessa State Academy of Building and Architecture, Odessa 